\title{
PANORAMA DAS PRODUÇÕES DIDÁTICO-PEDAGÓGICAS PRODUZIDAS PELOS PROFESSORES DE BIOLOGIA DO PROGRAMA DE DESENVOLVIMENTO EDUCACIONAL DO PARANÁ ${ }^{1}$
}

\author{
OVERVIEW OF DIDATIC-PEDAGOGICAL PRODUCTIONS PRODUCED BY \\ BIOLOGY TEACHERS OF EDUCATIONAL DEVELOPMENT PROGRAM OF PARANA
}

\author{
Daniela Frigo Ferraz ${ }^{2}$ \\ Fabio Seidel dos Santos ${ }^{3}$ \\ Antonio Carlos Frasson ${ }^{4}$ \\ Luiz Alberto Pilatti ${ }^{5}$ \\ Antonio Carlos de Francisco ${ }^{6}$
}

\section{Resumo}

O objetivo deste artigo foi analisar as produções didático-pedagógicas produzidas pelos professores de Biologia durante sua participação no Programa de Desenvolvimento Educacional (PDE) do estado do Paraná. Optou-se por uma abordagem exploratória e a análise documental como instrumento de coleta de dados. Foram encontradas 207 produções didático-pedagógicas. Dessas, a maioria (23\%) foi orientada por professores da Universidade Estadual do Oeste do Paraná (Unioeste-PR). Os conteúdos de saúde humana e ecologia foram os mais abordados (ambos 22\%), e as unidades didáticas foram as preferidas pelos professores (20\%). Contudo, a maioria das publicações (33\%) apresenta o formato das produções didático-pedagógicas indefinidas na sinopse. Conclui-se, a partir dos resultados, que os professores de Biologia também podem ser produtores de conhecimento, no lugar de apenas

\footnotetext{
${ }^{1}$ Apoio CAPES/Coordenação de aperfeiçoamento de pessoal de nível superior.

2 É professor Assistente do curso de Ciências Biológicas da Universidade Estadual do Oeste do Paraná. É membro da ABRAPEC (Associação Nacional de Pesquisadores em Educação em Ciências) e membro do GECIBIO (Grupo de Pesquisa em Educação em Ciências e Biologia) junto ao CNPq. E-mail: dfrigoferraz@gmail.com

${ }^{3} \mathrm{O}$ autor possui Mestrado em Ciências Biológicas (Biologia Evolutiva) pela Universidade Estadual do CentroOeste - UNICENTRO (2013). Atualmente cursa Doutorado em Ensino de Ciências e Tecnologia na Universidade Tecnológica Federal do Paraná - UTFPR Campus de Ponta Grossa. E-mail: fabio_seidel@hotmail.com

4 Doutor em Educação pela Universidade Metodista de Piracicaba. Professor Adjunto da Universidade Tecnológica Federal do Paraná - Ponta Grossa. É líder do grupo de pesquisa Educação Inclusiva: contextos de formação e práticas pedagógicas para o Ensino de Ciência e Tecnologia. Avaliador institucional e de cursos do Instituto Nacional de Estudos e Pesquisas Educacionais Anisio Teixeira - INEP. E-mail: ancafra@ gmail.com

5 Doutor em Educação Física pela Universidade Estadual de Campinas (UNICAMP). Professor Titular da Universidade Tecnológica Federal do Paraná (UTFPR). É líder do grupo de pesquisa Gestão de Recursos Humanos para o Ambiente Produtivo. E-mail: lapilatti@utfpr.edu.br

${ }^{6} \mathrm{O}$ autor é Doutor em Engenharia de Produção pela Universidade Federal de Santa Catarina (2003). Atualmente é Professor Titular do Ensino Básico, Técnico e Tecnológico da Universidade Tecnológica Federal do Paraná (UTFPR) e professor dos Programas de Pós-Graduação em Engenharia de Produção (Mestrado e Doutorado) e de Ensino de Ciência e Tecnologia (Mestrado Profissional) da UTFPR, Campus Ponta Grossa. Avaliador do INEP. E-mail: acfrancisco@gmail.com
} 
consumidores de materiais didáticos que, na maior parte dos casos, não são ligados aos problemas que se deparam na realidade de suas escolas.

Palavras-chave: Formação Continuada de Professores. Ensino de Biologia. Políticas Públicas Educacionais.

\begin{abstract}
The objective of this study was to analyze the didactic-pedagogical productions produced by biology teachers during their participation in the Educational Development Program (EDP) of State of Parana. We chose an exploratory approach and document analysis as instrument for the data collection. 207 didactic-pedagogical productions were found. Of these, the majority (23\%) was guided by professors from the State University of West Parana (Unioeste-PR). The human health and ecology themes were the most discussed (both 22\%), and teaching units were preferred by teachers $(20 \%)$. However, most publications $(33 \%)$ show the format of didactic-pedagogical productions undefined in the synopsis. In conclusion, we believe that biology teachers can also be producers of knowledge, rather than just consumers of educational materials, in most cases, are not linked to the problems facing the reality of their schools.
\end{abstract}

Key-words: Continuing Teacher Education. Teaching of Biology. Educational Public Policy.

\title{
1. Introdução
}

O Programa de Desenvolvimento Educacional do Paraná/ PDE foi idealizado durante a elaboração do Plano de Carreira do Magistério- Lei Complementar n 103/04 (PARANÁ, 2004) e estabelecido pelo Decreto $\mathrm{n}^{\circ}$. 4.482, de 14/03/05. O primeiro processo seletivo aconteceu em 2006 e o início das atividades em 2007. Todavia, a regulamentação deste programa aconteceu somente em 14 de julho de 2010, através da Lei Complementar $\mathrm{n}^{\circ} 130$ (OGLIARI, 2012).

O objetivo principal do programa é proporcionar aos professores da rede pública estadual do Paraná subsídios teórico-metodológicos para o desenvolvimento de ações educacionais sistematizadas, e que resultem em redimensionamento de sua prática. (PARANÁ, 2013a).

O PDE é considerado uma política de estado no Paraná, e está direcionado à formação continuada de professores, permitindo a integração entre professores de instituições do ensino superior e os da educação básica por meio de atividades teórico-práticas (PARANÁ, 2014b). A importância da formação continuada é indiscutível na área educacional, de modo geral, 
vários autores afirmam ser fundamental que os professores estejam em constante desenvolvimento profissional (NÓVOA, 1992; SCHÖN, 2000; TARDIF, 2013; GAUTHIER et al., 1998), haja vista as constantes mudanças que se dão na sociedade do conhecimento e consequentemente em suas áreas de atuação.

No caso do ensino de Biologia, segundo autores como Carvalho (2005), Pansera-de Araújo (2013), a produção desse conhecimento tem sido marcada, desde a segunda metade do século XX, pela inter-relação entre os aspectos ecológicos-evolutivos, tanto em nível macro quanto microscópico, bem como pelos estudos da Biologia celular e molecular, imunologia, microbiologia, bioquímica, biotecnologia. Esses estudos contribuem para a compreensão da organização e funcionamento dos seres vivos nas suas relações interespecíficas e ambientais. (BRASIL, 2006).

Segundo Pansera-de Araújo (2013), a contextualização é o ponto de partida para o estudo e a compreensão da Biologia pelo estudante e na medida em que o estudo do contexto torna-se central o mesmo passa a analisar e inter-relacionar o conhecimento necessário para explicar e entender a realidade.

No presente trabalho mostramos uma análise acerca do estado atual do conhecimento das produções didático-pedagógicas produzidas pelos professores de Biologia participantes do programa PDE no período compreendido entre os anos de ingresso no PDE de 2008 até 2012, visando proporcionar um panorama geral do que tem sido produzido nesses seis anos em que vem sendo desenvolvido o programa.

As produções didático-pedagógicas são materiais didáticos produzidos pelos professores participantes do programa visando a obter um trabalho mais voltado para o contexto da educação paranaense e vinculado aos conhecimentos específicos de suas áreas de atuação, no caso dos professores de biologia, o ensino dos conceitos biológicos.

Tendo em vista que o PDE já vem sendo desenvolvido desde o ano de 2007 no estado do Paraná, questionamos qual o estado atual de conhecimento acerca das produções didáticas dos professores de Biologia produzidas nesse programa até o presente momento? Justifica-se a importância dessa indagação já que se percebe que raramente é dada a oportunidade ao professor de biologia de se tornar autor de seus materiais didáticos de forma autônoma. $\mathrm{O}$ que ocorre, na maior parte dos casos, é que esse profissional apenas reproduz ou adequa materiais 
provindos de lugares que não condizem com a realidade daquela comunidade escolar. (ASSIS, 2013).

Para isso, inicialmente mostramos como está organizado o PDE no estado do Paraná, suas origens e estruturação do programa em suas diferentes etapas; sua inserção como política de formação continuada de professores no estado do Paraná e, por fim, discute-se como foram estruturadas e distribuídas as produções didático-pedagógicas produzidas pelos professores de biologia que participaram do programa com entrada até o ano de 2012.

\section{O Programa de Desenvolvimento Educacional/ PDE e a Estruturação das Produções Didático-Pedagógicas no Planejamento dos Professores}

Podem participar do PDE professores que se enquadram no plano de carreira nível II, ou seja, professores que tenham mais de 10 anos de tempo de serviço. Mediante a conclusão das atividades propostas pelo PDE, o professor poderá ascender ao último nível do plano de carreira, o Nível III, conforme previsto no Plano de Carreira do Magistério Estadual- Lei Complementar n 103/04 (PARANÁ, 2004). O programa tem duração de dois anos, assim o professor em exercício na educação básica tem garantido o direito ao total afastamento remunerado de suas atividades durante o primeiro ano e parcialmente $(25 \%)$ no segundo ano do programa. (OGLIARI, 2012).

De forma geral, o programa apresenta-se estruturado a partir de três eixos de atividades durante esses dois anos: atividades de integração teórico-práticas, atividades de aprofundamento teórico e atividades didático-pedagógicas com utilização de suporte tecnológico. Dentre as atividades previstas para o eixo um, o professor PDE deverá cumprir as seguintes atividades: 1) Projeto de intervenção pedagógica na escola; 2) Orientação nas IES (Instituições de Ensino Superior); 3) Produção Didático-Pedagógica, direcionada para a 4) Implementação do Projeto na Escola e 5) Trabalho final. (PARANÁ, 2013a).

Já o eixo dois visa "contribuir para o aprofundamento teórico das questões educacionais em geral e das questões específicas das disciplinas que compõem o currículo da Educação Básica da Rede Estadual” (PARANÁ, 2013a, p. 8). As atividades propostas para esse eixo compreendem cursos, eventos, encontros de área. O eixo três contempla a formação 
tecnológica do professor PDE ao promover a atividades e cursos que subsidiam o uso de recursos tecnológicos para o desenvolvimento das atividades previstas no programa. (PARANÁ, 2013a). A Figura 1 mostra a articulação desses três eixos no Programa de forma sintética.

Figura 1- Plano Integrado de Formação Continuada

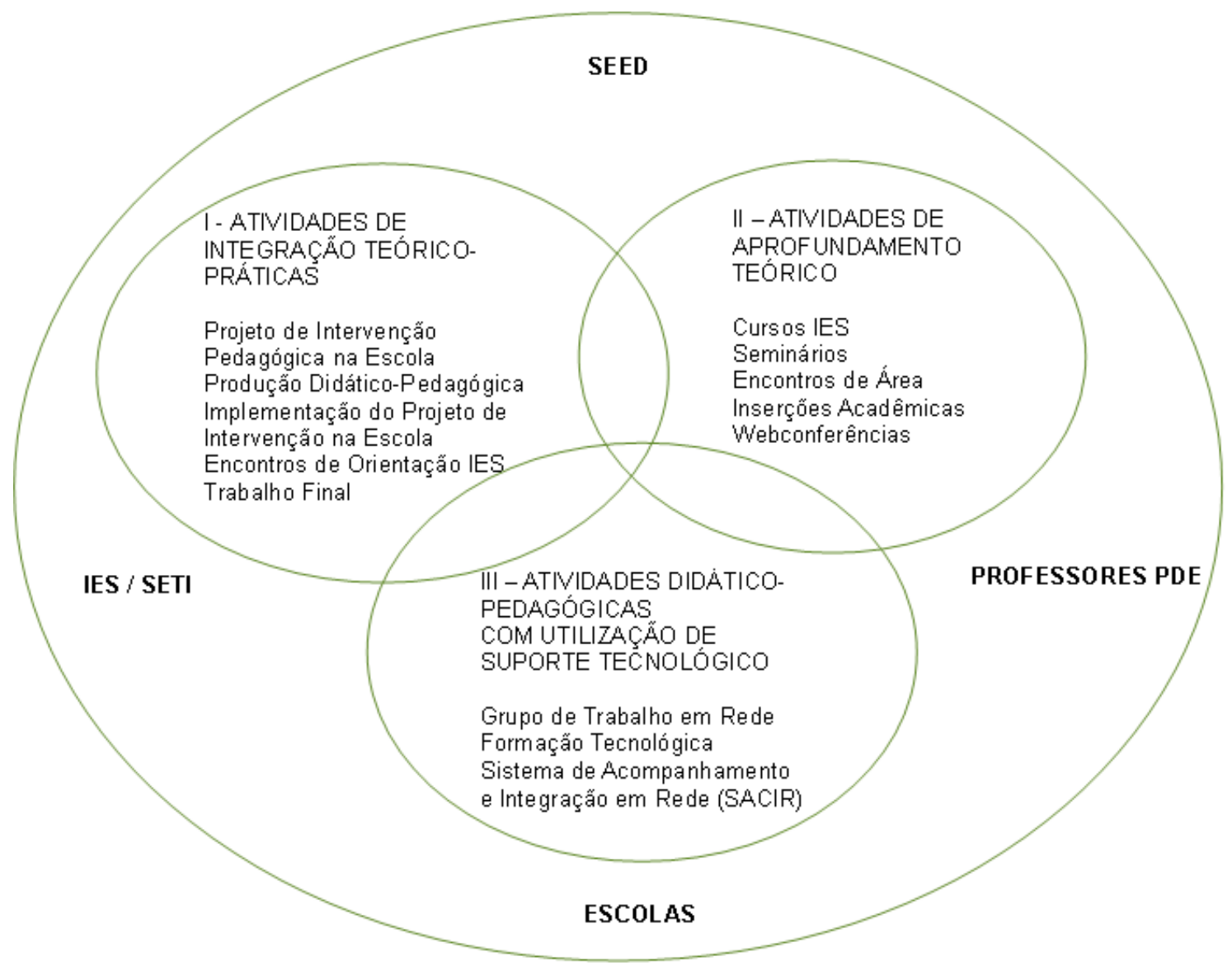

Fonte: Documento Síntese PDE 2013 (PARANÁ, 2013a).

No trabalho aqui apresentado optou-se por analisar as produções didático-pedagógicas dos professores da área de Biologia, atividade prevista no eixo um, para tanto nos deteremos em aprofundar esse tópico. Essas produções têm por objetivo buscar alternativas para a superação dos problemas encontrados pelos professores em suas práticas pedagógicas, no contexto de suas escolas, de suas salas de aula. 
[...] a Produção didático-pedagógica é uma elaboração teórica que toma um formato prático a ser implementada nesse contexto, com objetivos pertinentes a práxis, ou seja, a ação permeada pela reflexão teórica. Tal elaboração é também uma proposição com intenção cooperativa entre o professor e seus pares, ou entre o professor e os gestores, ou entre o professor e os alunos, pois visa contribuir com estes [...]. (PARANÁ, 2013b, p. 1).

Desta forma, necessita contemplar, segundo manual SEED para elaboração da produção didática (PARANÁ, 2013b): a) Relação da Produção com a área/disciplina de atuação do Professor PDE; b) Estreita articulação da Produção com o Projeto de Intervenção Pedagógica na Escola elaborado pelo Professor PDE; c) Perspectiva de contribuição da Produção Didático-pedagógica na superação dos problemas relacionados ao processo ensinoaprendizagem identificados da escola; d) Viabilidade de utilização da produção, considerando o contexto da escola onde será aplicada; e) Compatibilidade de linguagem, forma e conteúdo da Produção com o público a que se destina; f) Possibilidade de ser incorporada às práticas pedagógicas da escola pública paranaense.

Além disso, essas produções didáticas estão estruturadas contendo alguns componentes que são: uma ficha de identificação da produção didática, nessa encontram-se os dados de identificação do professor PDE, da IES, o resumo e o público a que se destina o material; uma apresentação do material, na qual são descritos os objetivos da produção; a proposta do material didático, contemplando o conteúdo específico a ser desenvolvido e as formas de avaliação adotadas; as orientações metodológicas, que visam a orientar os demais professores que queiram utilizar o material; as referências utilizadas para a elaboração do material didático. (PARANÁ, 2013b).

Esses materiais podem assumir diferentes formatos, que também são descritos no manual SEED para elaboração da produção didática (PARANÁ, 2013b), no entanto, é esclarecido que são apenas sugestões de formatos, podendo o professor e seu orientador optar por outros se achar mais adequado. Dentre os formatos possíveis descritos no manual de 2013 encontram-se as Unidades Didáticas, os Cadernos Pedagógicos e os Cadernos Temáticos.

As Unidades Didáticas caracterizam-se por desenvolver um tema, aprofundando-o de forma teórica e metodológica. Compreende um ou mais conteúdos da disciplina ou área do professor PDE. São planejadas a partir de uma perspectiva metodológica para o público alvo da implementação do projeto de intervenção na escola. Os Cadernos Pedagógicos são os 
materiais didáticos compostos por várias Unidades Didáticas, mantendo o foco nos conteúdos disciplinares específicos. Por fim, os Cadernos Temáticos, objetivam ao aprofundamento teórico de um tema específico.

Não podemos deixar de lembrar que existiam outros formatos possíveis de produções didáticas quando o programa teve início em 2007. No Documento Síntese da época (PARANÁ, 2007) indicava-se para elaboração desses materiais, além dos descritos anteriormente, o Objeto de Aprendizagem Colaborativa (OAC), que se destinava a fundamentar o trabalho dos professores; e o Folhas de caráter didático, que podia ser utilizado como material de apoio para o trabalho com os alunos. Essas produções tinham como foco os conteúdos disciplinares previstos para a Rede Pública Estadual. Conforme Possi (2012, p. 103):

\begin{abstract}
A elaboração do material didático privilegia os conteúdos estruturantes das Diretrizes Curriculares do Estado do Paraná articulado com o local, ou seja, a escola de atuação e os conteúdos disciplinares previstos para a Rede Pública Estadual. Esses materiais didáticos têm por finalidade tornar o professor PDE/PR produtor de conhecimento, ao invés de ser apenas um reprodutor. A proposta de intervenção na escola privilegia a articulação teoria-prática, sendo uma potencialidade do programa.
\end{abstract}

Pondera-se que ao se tornar produtor de conhecimento o professor atuará de forma mais autônoma e crítica em relação ao contexto de sua atuação, de sua prática pedagógica, para isso deve estar constantemente refletindo na e sobre sua ação (SCHÖN, 2000; PIMENTA; GHEDIN, 2002). É imperativo repensar o papel do professor no sentido de formar um profissional crítico, que mantém relação de envolvimento com sua prática, envolvimento esse que contribui no debate social sobre as intenções e finalidade da escola na sociedade e como não poderia deixar de ser, sobre a importância de desenvolver um Ensino de Biologia adequado às necessidades atuais.

Sacristán e Pérez-Gómez (1998) apontam alguns critérios que o professor deve considerar ao planejar a sua ação pedagógica, de modo a refletir e deliberar sobre a prática a ser desenvolvida e de modo a atender aos dilemas fundamentais frente aos quais deve optar. São eles: 


\begin{abstract}
a) Pensar e refletir sobre a prática antes de realizá-la; b) Considerar que elementos intervêm na configuração da experiência que os alunos/as terão, de acordo com a peculiaridade do conteúdo curricular envolvido; c) Ter em mente as alternativas disponíveis: lançar mão de experiências prévias, casos, modelos metodológicos, exemplos realizados por outros; d) Prever, na medida do possível, o curso da ação que se deve tomar; e) Antecipar as consequências possíveis da opção escolhida no contexto concreto em que se atua; f) Ordenar os passos a serem dados, sabendo que haverá mais de uma possibilidade; g) Delimitar o contexto, considerando as limitações com que contará ou tenha de superar, analisando as circunstâncias reais em que se atuará: tempo, espaço, organização de professores/as, alunos/as, materiais, meio social, etc.; h) Determinar ou prover os recursos necessários. (SACRISTÁN; PÉREZ-GÓMEZ, 1998, p. 205).
\end{abstract}

Considera-se que é de fundamental importância o papel do professor em desenvolver o planejamento de suas ações didáticas e curriculares considerando a complexidade da realidade em que irá atuar, ou seja, a importância de considerar o contexto de sua atuação. Para isso, como destacado nos grifos dos autores deve-se antecipar a sua ação pedagógica e considerar os diferentes fatores que poderão se deparar e desenhar suas ações a partir desses fatores. Segundo Contreras (2002), os professores devem decidir como planejar suas aulas, considerando as singularidades das situações educativas que não deveriam ser prescritas unicamente pelas instâncias superiores.

Além disso, as produções didáticas podem ser consideradas como uma forma alternativa ao uso do livro didático nas aulas dos professores. Se considerarmos que o professor dispõe de uma série de recursos didáticos e metodologias, é importante que o mesmo habitue-se a planejar suas ações didáticas por meio da produção de materiais didáticos alternativos. Segundo Assis (2013, p. 67), “[...] pensar em autoria de materiais didáticos nos sugere antes refletir sobre autonomia docente, o que implica considerar fatores sociais e institucionais que condicionam a prática educativa e que estão intrinsecamente relacionados a esta".

No entanto, para que esse planejamento seja viável, o professor deve dispor de tempos, espaços e recursos materiais e financeiros para incorporar essas atividades em sua rotina. $\mathrm{O}$ tempo e o espaço, bem como os recursos financeiros dispendidos com os professores no PDE possibilita ao mesmo desenvolver essas ações, sendo que no período de 2007 a 2010, segundo Hochuli $(2011$; 2013), foram gastos um total de R\$ 351.407.049,01 entre as diferentes rubricas necessárias à execução do programa, e o custo-aluno PDE é de R\$29. 480, 46. 
A questão da temporalidade é corroborada por Possi (2012) tomando como base Tardif (2013) ao destacar que a aprendizagem é um processo, o qual demanda um longo tempo em que os saberes vão sendo incorporados progressivamente. Desse modo, os saberes que o professor incorpora durante o período cursado no programa PDE, no espaço da universidade, demanda tempo para ser transposto para o cotidiano escolar. Segundo Possi (2012, p. 112):

Trata-se de um programa que apresenta avanços significativos. Sem dúvida, merece destaque o fato de o professor ter tempo para estudar, voltar a universidade, reunir com seus pares, com seu orientador na IES, planejar uma intervenção que atenda as demandas do seu lugar de atuação.

Para que isso ocorra de forma satisfatória, segundo Ogliari (2012), a Secretaria de Estado da Educação do Paraná procura disponibilizar as condições necessárias para uma efetiva formação do professor, conforme indicam os estudos sobre a formação dos professores, desse modo, o programa prevê:

\begin{abstract}
Afastamento do professor da atividade de docência sem perda de vencimentos; a disponibilidade de todas as universidades públicas do estado do Paraná; a remuneração dos professores orientadores e aqueles que ministram cursos para o PDE; estrutura física própria para o PDE em todas as universidades estaduais, contendo salas de aula, laboratórios de informática, auditório, biblioteca, além da própria estrutura já existente das instituições de ensino superior; a garantia, no segundo ano do PDE, de carga horária docente para a implementação do projeto na escola, a socialização dos estudos do professor para os demais professores do estado por meio do GTR e das publicações virtuais dos cadernos PDE [...]. Isto representa a ruptura com formações pontuais, desvinculadas da realidade dos professores. (OGLIARI, 2012, p. 5864).
\end{abstract}

Segundo Assis (2013), o afastamento remunerado do professor não é apenas um incentivo financeiro aos professores, mas antes de tudo um investimento intelectual na educação pública, que vislumbra melhorias para o processo de ensino e de aprendizagem como um todo. Além disso, segundo a autora, nesse momento o professor também pode repensar sua prática, reavaliar suas metodologias e estratégias de ensino, perceber os aspectos positivos e limitantes de suas ações didáticas, conhecer e desenvolver novas metodologias e adaptá-las para o cotidiano escolar.

\title{
3. Aspectos Metodológicos
}

Trata-se de um estudo em que se optou por uma abordagem quanti-qualitativa, já que segundo autores como Santos Filho e Gamboa (1995), é reconhecida a complementaridade 
entre ambos paradigmas, sendo incorreto assumir, segundo Bauer e Gaskell (2002) que a pesquisa qualitativa possui o monopólio da interpretação, com o pressuposto paralelo de que a pesquisa quantitativa chega a suas conclusões quase que automaticamente. Foi realizada uma pesquisa exploratória nas produções didático-pedagógicas da área de Biologia produzidas pelos professores PDE que ingressaram nos anos de 2008, 2009, 2010 e de 2012, ficando fora somente o ano de 2007 por falta de disponibilidade das sinopses no Portal Dia a Dia Educação.

Segundo Gil (2002), o estudo exploratório permite obter uma visão geral do fato estudado, o objetivo principal desse tipo de estudo é o aprimoramento de ideias ou a descoberta de intuições. Para a coleta de dados procedeu-se a uma análise documental, que segundo esse mesmo autor, caracteriza-se por utilizar documentos que não receberam nenhum tratamento analítico, como por exemplo, documentos conservados em órgãos públicos, como é o caso dos documentos selecionados para essa investigação.

As produções didático-pedagógicas selecionadas para este estudo encontram-se alocados no Portal "Dia a Dia Educação" da Secretaria de Estado da Educação do Paraná (SEED). Considera-se importante a fidedignidade das ideias, técnicas e estratégias realmente expressas nos documentos analisados, pois são fontes primárias de dados, conforme afirma Gil (2002).

Nesta perspectiva, optou-se por analisar as sinopses das produções didáticopedagógicas de forma quanti-qualitativa, levando em consideração os seguintes eixos de análise: número total de produções; número de produções por Instituição de Ensino Superior (IES); formato e conteúdo das produções e IES dos orientadores.

\section{Resultados e Discussões}

Foram 207 produções didático-pedagógicas da área de Biologia produzidas nos anos de 2008, 2009, 2010 e 2012. Desconsideraram-se as produções publicadas em 2007, pois não se encontram disponíveis ao público no Portal Dia a Dia Educação (http://www.diaadia.pr.gov.br/), conforme informado. 
Entre as produções analisadas, foram encontrados trabalhos orientados por professores da Universidade Estadual do Oeste do Paraná (UNIOESTE), Universidade Estadual de Maringá (UEM), Universidade Estadual de Londrina (UEL), Universidade Estadual do Centro-Oeste (UNICENTRO), Universidade Norte do Paraná (UNOPAR), Universidade Federal do Paraná (UFPR), Universidade Estadual de Ponta Grossa (UEPG), Faculdade de Estadual de Filosofia Ciências e Letras de União da Vitória (FAFIUV), Universidade Tecnológica Federal do Paraná (UTFPR), Faculdade Estadual de Educação, Ciência e Letras de Paranavaí (FAFIPA) e Universidade Estadual do Norte do Paraná (UENP). O mapa da Figura 2 mostra a distribuição das orientações por IES.

Figura 2 - Mapa do Estado do Paraná mostrando a localização espacial do campus central das IES analisadas e os percentuais de orientação dos professores PDE em cada universidade.

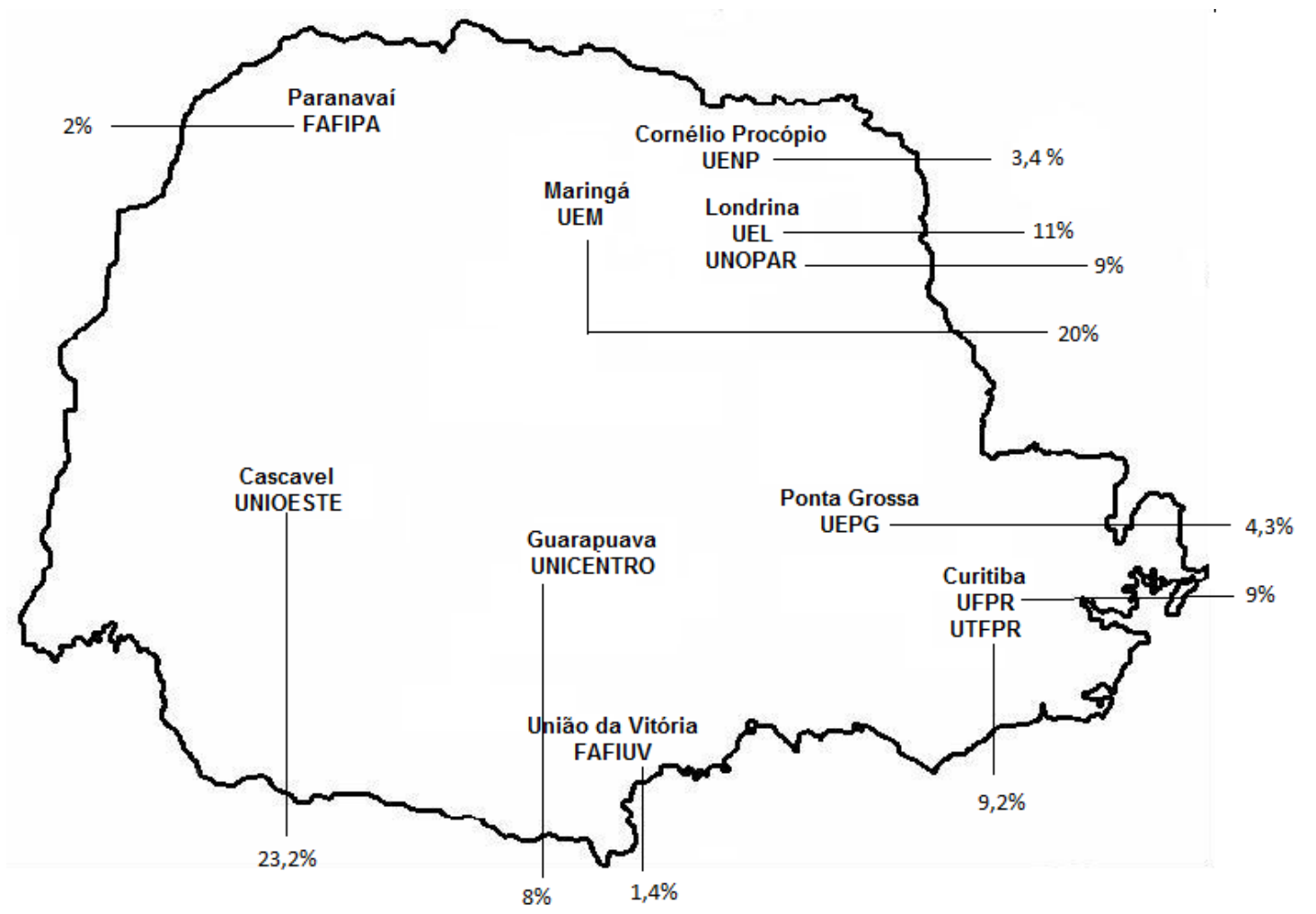

Fonte: Dados da pesquisa 2014.

A maioria das produções foi orientada por professores da UNIOESTE e UEM, com $23 \%$ e $20 \%$ das publicações, respectivamente. Os professores da FAFIUV, FAFIPA e UENP 
orientaram a minoria das produções. Uma das possíveis justificativas para o fato dos professores das três maiores universidades estaduais paranaenses (UEM, UNIOESTE e UEL) orientarem a maioria das produções é a de que o PDE envolve $80 \%$ dos professores das instituições estaduais, e os $20 \%$ restantes são provenientes da Universidade Federal do Paraná (UFPR) e Universidade Tecnológica Federal do Paraná (UTFPR) (KADRI; CAMPOS; SOUZA, 2011, p. 123). A Tabela 1 mostra com maiores detalhes esta questão. Além disso, segundo Ogliari (2012), o programa prevê a disponibilidade de todas as universidades públicas do estado do Paraná, bem como a remuneração dos professores orientadores e aqueles que ministram cursos para o PDE; e estrutura física própria para o PDE em todas as universidades estaduais, contendo salas de aula, laboratórios de informática, auditório, biblioteca entre outros.

Tabela 1 - Número de produções didático-pedagógicas por IES.

\begin{tabular}{|c|c|c|c|c|c|c|}
\hline \multirow{2}{*}{ IES } & \multicolumn{4}{|c|}{ Ano da publicação das sinopses } & \multirow[b]{2}{*}{ Total } & \multirow{2}{*}{$\%$} \\
\hline & 2008 & 2009 & 2010 & 2012 & & \\
\hline UNIOESTE & 6 & 13 & 8 & 21 & 48 & 23,2 \\
\hline UEM & 6 & 10 & 12 & 14 & 42 & 20 \\
\hline UEL & 3 & 9 & 7 & 4 & 23 & 11 \\
\hline UTFPR & 8 & 6 & 4 & 1 & 19 & 9,2 \\
\hline UFPR & 7 & 1 & 8 & 2 & 18 & 9 \\
\hline UNOPAR & 3 & 11 & - & 4 & 18 & 9 \\
\hline UNICENTRO & 3 & 5 & 4 & 4 & 16 & 8 \\
\hline UEPG & 1 & 2 & 5 & 1 & 9 & 4,3 \\
\hline UENP & - & - & 7 & - & 7 & 3,4 \\
\hline FAFIPA & - & - & 4 & - & 4 & 2 \\
\hline FAFIUV & - & 1 & 1 & 1 & 3 & 1,4 \\
\hline Total & 37 & 58 & 60 & 52 & 207 & \\
\hline
\end{tabular}

Fonte: Dados da pesquisa 2014.

A respeito do conteúdo das publicações, optou-se por classificá-las conforme os principais ramos da Biologia. Os resultados mostram que os professores apresentaram uma 
maior preferência pelos conteúdos relacionados à saúde humana (sexualidade e nutrição) e ecologia (biodiversidade, conservação e educação ambiental).

Os problemas relacionados à alimentação inadequada, droga, sexualidade e questões ambientais são problemas sociais contemporâneos que, segundo as Diretrizes Curriculares da Educação Básica, devem ser “[...] abordados pelas disciplinas que lhes são afins, de forma contextualizada, articulados com os respectivos objetos de estudo dessas disciplinas e sob o rigor de seus referenciais teórico-conceituais”. (PARANÁ, 2008, p. 26).

A sexualidade do adolescente foi um tema bastante abordado pelos professores em suas produções. Segundo as Diretrizes Curriculares Nacionais da Educação Básica, reflexões e debates sobre a sexualidade precisam ser inseridos no projeto político pedagógico das escolas Ensino Médio (BRASIL, 2013). O conhecimento mais amplo e desmistificado sobre seu próprio corpo pode contribuir para a formação da autoestima do adolescente, bem como para o desenvolvimento de comportamentos de respeito ao próprio corpo e aos dos outros e para a compreensão da sexualidade humana como algo natural livre de preconceitos. (BRASIL, 2000).

Verifica-se a preocupação de que os temas abordados pelos professores em suas produções didáticas estejam relacionados ao contexto de atuação do professor, visando a relacionar os conceitos científicos com a realidade dos alunos das escolas paranaenses, como no caso de temas como alimentação, drogas, sexualidade, educação ambiental. Apesar de serem temas sociais contemporâneos, ou seja, que atingem os mais diversos contextos sociais e educacionais, vinculam-se a essas realidades de forma mais específica já que os materiais são pensados a partir da realidade das escolas onde atuam esses professores. Segundo Pansera-de Araújo (2013), isso é um aspecto essencial no ensino de Biologia, já que na medida em que o estudo do contexto torna-se central o aluno passa a analisar e interrelacionar o conhecimento científico necessário para explicar e entender a realidade.

O tema "educação ambiental" foi fortemente abordado em produções na área de ecologia, uma área que desperta bastante interesse pelos professores de ciências biológicas. Em um estudo com professores de ciências, Lima e Vasconcelos (2008) constataram que a área de Ecologia, especialmente os temas educação ambiental e conservação, estão entre as mais atrativas para os professores que buscam uma especialização. Segundo os autores, esta 


\section{9}

Panorama das produções didático-pedagógicas produzidas pelos professores de biologia...

preferência possivelmente está vinculada à tendência mundial em aprofundar o debate sobre temas relacionados ao uso sustentável da natureza e à preservação ambiental.

A educação ambiental é um movimento surgido em meados do século passado. Refere-se à preservação, conservação e recuperação ambiental. Trata-se de uma forma de educação que pode levar a mudança de comportamento dos alunos, de maneira a sensibilizálos quanto aos problemas ambientais que podem comprometer o futuro da humanidade (ASSIS, 2013). Embora seja importante a discussão de temas relacionados à Educação Ambiental no ensino de Biologia, autores ressaltam que este é um tema multidisciplinar e pode ser trabalhado por professores de variadas áreas do conhecimento. (ASSIS, 2013; RODRIGUES et al., 2012).

Em segundo lugar, encontraram-se produções cujos conteúdos encaixam-se nos ramos da biologia celular, genética e biologia geral, sendo esta última assim denominada em função da falta de especificidade do conteúdo da produção didático-pedagógica. Os principais resultados referentes ao conteúdo das produções encontram-se em detalhes na Figura 3.

Figura 3 - Conteúdo das produções didático-pedagógicas. Os dados representam o somatório das produções publicadas em 2008, 2009, 2010 e 2012.

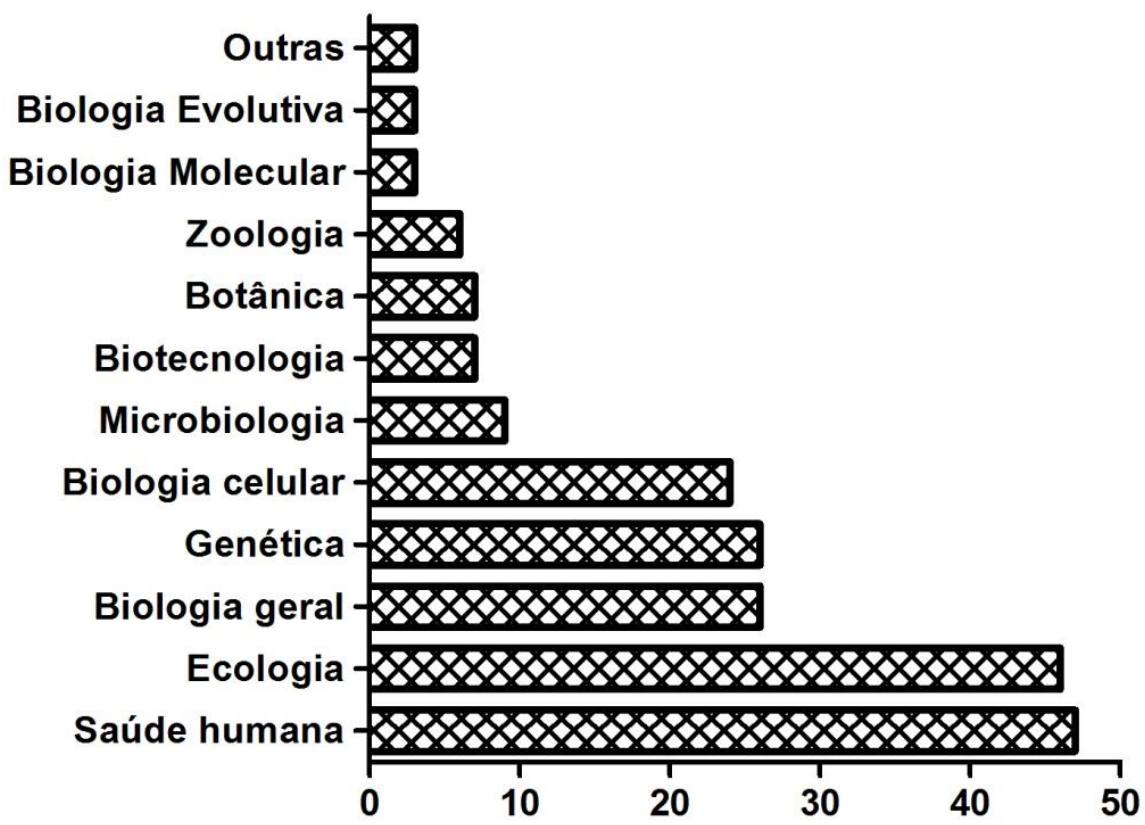

Fonte: Dados da pesquisa 2014. 
Entre os formatos das publicações (Figura 4), os resultados mostraram que a maioria dos professores classifica suas produções como unidades didáticas (20\%). Os materiais digitais (apresentações em Power Point, Blogs, softwares, vídeos entre outros) foram escolhidos por $11 \%$ dos professores. Contudo, percebeu-se que a maioria das publicações (33\%) apresentam o formato das produções didático-pedagógicas indefinidas na sinopse, refletindo uma certa imaturidade na escrita de materiais científicos.

Figura 4 - Formato das produções didático-pedagógicas. Os dados representam o somatório das produções publicadas em 2008, 2009, 2010 e 2012.

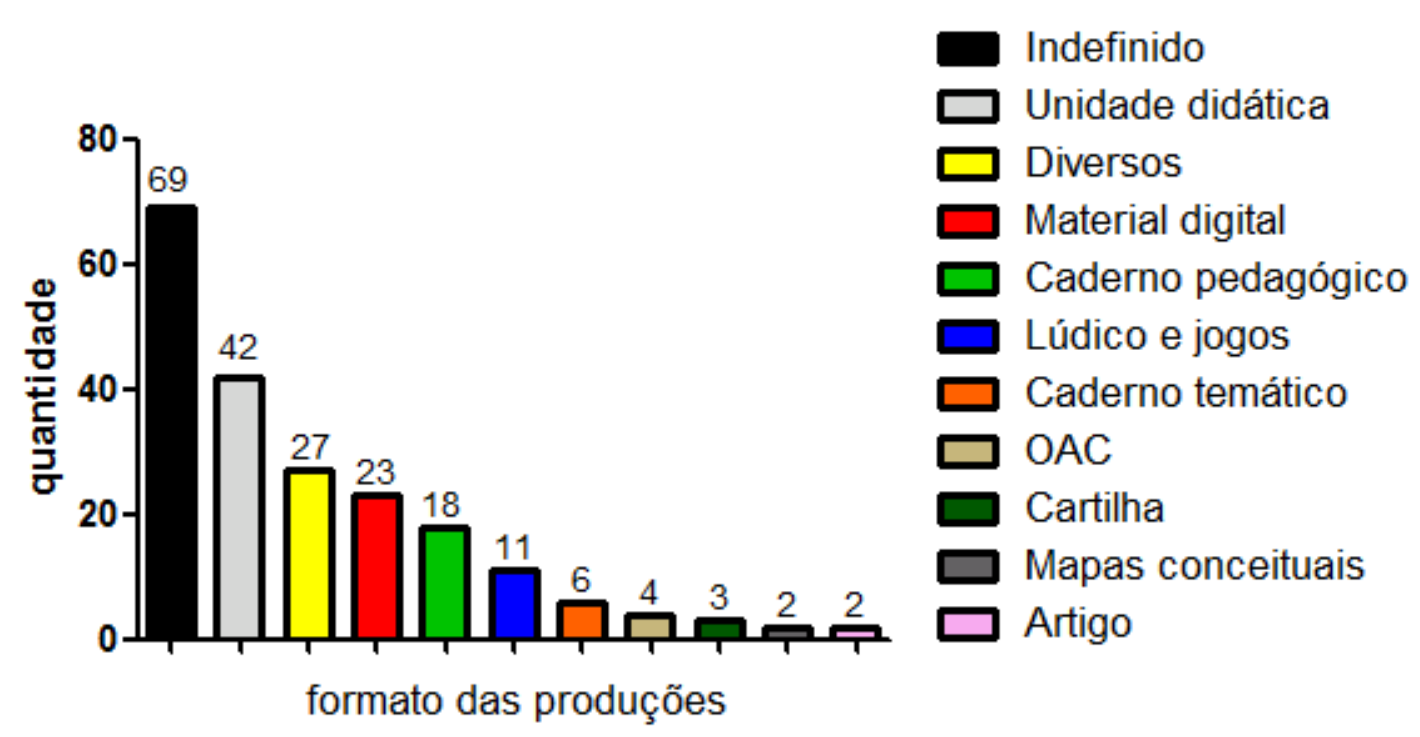

Fonte: Dados da pesquisa 2014.

O planejamento e a construção dos materiais didático-pedagógicos são atividades práticas do professor e devem ser cuidadosamente realizadas. Segundo Pereira (2011), os materiais didático-pedagógicos devem:

cumprir diferentes papéis, apresentar conteúdos específicos e orientar o estudante na trajetória de cada disciplina e no curso como um todo. Desse modo, ele precisa estar em consonância com o projeto político-pedagógico do curso, considerar as habilidades e competências específicas a serem desenvolvidas pelos alunos e recorrer a um conjunto de mídias compatível com a proposta e com o contexto socioeconômico do público-alvo. (PEREIRA, 2011, p. 46). 
Estes recursos de natureza diversa (material digital, unidades didáticas, cadernos pedagógicos, entre outros) se estabelecem como um material alternativo ao livro didático e apresentam a função principal de ampliar a capacidade de entendimento dos alunos. Além disso, são materiais planejados e vinculados ao contexto de atuação do professor, contendo estratégias e recursos voltados para os problemas enfrentados no seu cotidiano, o que segundo autores como Schön (2000), Pimenta e Ghedin (2002), Assis (2013) e Contreras (2002), é uma maneira para que o professor venha a atuar de forma mais autônoma e crítica em relação ao contexto de sua atuação, sendo que esse envolvimento com sua prática contribui para o debate social sobre as intenções e finalidade da escola.

\section{Considerações Finais}

Os resultados encontrados na presente investigação demonstram que existe uma quantidade razoável de produções didático-pedagógicas produzidas desde o início do programa PDE até o ano de 2012/2013, evidenciando que os professores de Biologia podem ser produtores de conhecimento, no lugar de apenas consumidores de materiais didáticos que, na maior parte dos casos, não são ligados aos problemas com que se deparam na realidade de suas escolas, de suas salas de aula.

Para que isso seja possível, é necessário que haja um investimento no trabalho de planejamento e implementação de materiais didáticos alternativos, como no caso das produções didático-pedagógicas produzidas no contexto do PDE, o que exige também tempo e espaços disponíveis para que se concretize.

A preferência pelo formato de Unidade Didáticas é visível, inferindo-se que isso se deva às possibilidades diversas de escolhas em termos metodológicos e de recursos didáticos, e também por ser um formato mais ligado ao trabalho que o professor já desenvolve em sala de aula, a partir de seus saberes experienciais (TARDIF, 2013), porém de forma não sistematizada.

Evidencia-se, ainda, que houve uma adesão por parte das IES públicas no desenvolvimento do programa, possibilitando o retorno do professor de Biologia à universidade, promovendo uma formação processual em serviço e não de forma aligeirada e 
pontual, permitindo a relação e reflexão teórico-prática a partir de sua ação, ou seja, de sua práxis como forma de atuação.

Os temas abordados nas produções didático-pedagógicas dos professores de Biologia são relacionados aos mais diversos ramos da Biologia, havendo uma maior preferência pelos conteúdos relacionados à saúde humana e ecologia e refletindo as preocupações atuais da sociedade em geral a respeito de problemas sociais como gravidez precoce, doenças sexualmente transmissíveis, obesidade e outros problemas relacionados à alimentação inadequada, poluição ambiental, entre outros.

Sugere-se uma investigação que aprofunde a análise do conteúdo desses materiais, de modo a verificar sua relação com os conhecimentos produzidos no campo da Didática das Ciências (CARVALHO, 2009; CACHAPUZ et al., 2005, entre outros), verificando a partir do sequenciamento didático e das opções metodológicas o quanto se articulam com as linhas de investigação contidas no campo de pesquisa da Didática da Ciência, já que esse campo está fundamentado em alguns pressupostos que deveriam ser considerados no ensino dos conceitos científicos no contexto da educação básica, principalmente quando se fala em processos de formação continuada de professores dessa mesma área de referência.

\section{Referências}

ASSIS, A. R. S. Discussão crítica sobre educação ambiental e o ensino de biologia para a prática social. In: Geoambiente on-line, Jataí-GO, n. 21, p. 108-126, jul./dez. 2013.

ASSIS, K. K. A articulação entre o ensino de ciências e as TIC: uma análise de materiais didáticos digitais produzidos por professores. Dissertação (Mestrado em Ensino de Ciências e Matemática) - Universidade Federal do Paraná, Curitiba, 2013.

BAUER, M. W.; GASKELL, G. Pesquisa qualitativa com texto, imagem e som: um manual prático. Trad. O de Pedrinho A. Guareschi. Petrópolis, RJ: Vozes, 2002.

BRASIL. Orientações curriculares para o ensino médio. Ciências da natureza, matemática e suas tecnologias. Brasília: Ministério da Educação; Secretaria de Educação Básica, 2006. 135p. Disponível em:

<http://portal.mec.gov.br/seb/arquivos/pdf/book_volume_02_internet.pdf> Acesso em: 18 de ago. 2014.

. Ministério da Educação e Desporto. Parâmetros Curriculares Nacionais para o

Ensino Médio (PCNEM). Brasília: MEC, 2000. 
BRASIL. Diretrizes Curriculares Nacionais da Educação Básica. Brasília: MEC, 2013.

CACHAPUZ, A.; GIL-PEREZ, D.; CARVALHO, A. M. P. de; PRAIA, J.; VILCHES, A. A necessária renovação do ensino das ciências. São Paulo, SP: Cortez, 2005. 263 p.

CARVALHO, G. S. de. A transposição didática e o ensino de biologia. In: CALDEIRA, A. M. de A.; ARAUJO, E. S. N. N. de. Introdução à didática da biologia. São Paulo, SP: Escrituras, 2009. (Educação para a Ciência; 10). p. 34-57.

CARVALHO, L. M. de. A temática ambiental e o ensino de biologia: compreender, valorizar e defender a vida. In: MARANDINO, M.; SELLES, S. E.; FERREIRA, M. S.; AMORIM, A. C. R. de. (Org.). Ensino de Biologia: conhecimentos e valores em disputa. Niterói, RJ: Eduff, 2005.

CONTRERAS, J. A autonomia dos professores. São Paulo, SP: Cortez, 2002.

GAUTHIER, C.; MARTINEAU, S.; DESBIENS, J. F.; MALO, A.; SIMARD, D. Por uma teoria da pedagogia: pesquisas contemporâneas sobre o saber docente. Trad. de Francisco Pereira. Ijuí, RS: Ed. Unijuí, 1998. 457p.

GIL, A. C. Como elaborar projetos de pesquisa. 4. ed. São Paulo, SP: Atlas, 2002.

HOCHULI, E. B. PDE - Programa de Desenvolvimento Educacional do Paraná. Monografia (Especialização em Políticas e Gestão da Educação) - Universidade Federal do Paraná, Curitiba, 2011.

PDE/PR- Programa de Desenvolvimento Educacional do Paraná. In: XI Congresso Nacional de Educação/ EDUCERE. Curitiba: PUC, 2013.

KADRI, M. S. E.; CAMPOS, A. G.; SOUZA, A. G. F. Modelo de Formação Continuada do PDE - PR: o diálogo necessário entre escola básica e ensino superior? Entretextos, Londrina, v. 11, n. 2, p. 121-141, jul./dez. 2011.

LIMA, K. E. C.; VASCONCELOS, S. D. O professor de ciências das escolas municipais de Recife e suas perspectivas de educação permanente. Ciência \& Educação, v. 14, n. 2, p. 347364, 2008.

NÓVOA, A. Formação de professores e profissão docente. In: NÓVOA, A. (Coord.) Os professores e sua formação. Lisboa: Publicações Dom Quixote,1992.

OGLIARI, C. R. N. PDE/PR - Programa de Desenvolvimento Educacional do Paraná: considerações sobre sua concepção e currículo. In: XVI ENDIPE - Encontro Nacional de Didática e Práticas de Ensino - UNICAMP. Campinas, SP: Junqueira \& Marin Editores, 2012. Livro 2. 
PARANÁ (Estado). Lei Complementar n. 103/2004, de 15/03/2004. Plano de Carreira do Professor da Rede Estadual de Educação Básica do Paraná. Diário Oficial do Estado, Curitiba, n. 6.687, 15 mar. 2004.

2008.

Diretrizes curriculares da educação básica - Biologia. Curitiba, PR: SEED/DEB,

Portal educacional do Estado do Paraná. Dia a dia educação. Projeto Folhas.

Disponível em:

<http://www.gestaoescolar.diaadia.pr.gov.br/modules/conteudo/conteudo.php?conteudo=20>. Acesso em: 20 jul. 2014.

PARANÁ (Estado). Secretaria de Estado da Educação/ SEED. Superintendência da Educação/ SUED. Diretoria de políticas e programas educacionais/ DPPE. Documento Síntese PDE. 2013a.

Secretaria de Estado da Educação/ SEED. Superintendência da Educação/ SUED. Diretoria de políticas e programas educacionais/ DPPE. Manual produção didáticopedagógica PDE. $2013 \mathrm{~b}$.

. Uma nova Política de Formação Continuada e Valorização dos Professores da Educação Básica da Rede Pública Estadual. Documento Síntese. 2007. Disponível em: $<$ http://www.pde.pr.gov.br/arquivos/File/pdf/ documento_sintese.pdf $>$ Acesso em: 13 ago. 2014.

PANSERA-DE ARAÚJO, M. C. Reflexões sobre os conhecimentos biológicos e pedagógicos constitutivos do professor no trabalho de sistematização do ensino de biologia. In: DUSO, L.; HOFFMANN, M. B. (Org.) Docência em Ciências Biológicas: propostas para um continuado (re) iniciar. Ijuí: Ed Unijuí, 2013. (Coleção Educação em Ciências).

PEREIRA, M. F. Modelo de produção de material didático: o uso da notação BPMN em curso a distância. RAI - Revista de Administração e Inovação, São Paulo, v. 8, n. 4, p. 45-66, out./dez. 2011.

PIMENTA, S. G.; GHEDIN, E. Professor reflexivo no Brasil: gênese e crítica de um conceito. São Paulo, SP: Cortez, 2002. 224p.

POSSI, E. H. de B. Programa de Desenvolvimento Educacional- PDE/PR (2007-2009): um estudo sobre as transformações e permanências. Dissertação (Mestrado em Educação. Universidade Estadual de Londrina), Londrina, 2012.

RODRIGUES, F. F. dos S. et al. Educação ambiental nos livros didáticos de biologia do ensino médio. Cadernos da FUCAMP, v. 11, n. 15, p. 147-154, 2012. 
65 Panorama das produções didático-pedagógicas produzidas pelos professores de biologia...

SACRISTÁN, J. G.; PÉREZ-GOMEZ, A. I. Compreender e transformar o ensino. Trad. Ernani F. da Fonseca Rosa. 4. ed. Porto Alegre, RS: Artmed, 1998. 396p.

SANTOS FILHO, J. C. dos; GAMBOA, S. S. Pesquisa educacional: quantidade-qualidade. São Paulo, SP: Cortez, 1995. (Questões da nossa época).

SCHÖN, D. A. Educando o profissional reflexivo: um novo design para o ensino e a aprendizagem. Trad. Roberto Cataldo Costa. Porto Alegre, RS: Artes Médicas Sul, 2000.

TARDIF, M. Saberes docentes e formação profissional. 13. ed. Petrópolis, RJ: Vozes, 2013. $325 p$. 